\title{
Structural Characterization of Oxidized Glycerophosphatidylserine: Evidence of Polar Head Oxidation
}

\author{
Elisabete Maciel, Raquel Nunes da Silva, Cláudia Simões, Pedro Domingues, \\ M. Rosário M. Domingues \\ Mass Spectrometry Centre, QOPNA, Department of Chemistry, University of Aveiro, 3810-193 Aveiro, Portugal
}

\begin{abstract}
Non-oxidized phosphatidylserine (PS) is known to play a key role in apoptosis but there is considerable research evidence suggesting that oxidized PS also plays a role in this event, leading to the increasing interest in studying PS oxidative modifications. In this work, different PS (1-palmitoyl-2-linoleoyl-sn-glycero-3-phospho-L-serine (PLPS), 1-palmitoyl-2-oleoyl-sn-glycero-3-phospho-L-serine (POPS), and 1,2-dipalmitoyl-sn-glycero-3-phospho-L-serine (DPPS) were oxidized in vitro by hydroxyl radical, generated under Fenton reaction conditions, and the reactions were monitored by ESI-MS in negative mode. Oxidation products were then fractionated by thin layer chromatography (TLC) and characterized by tandem mass spectrometry (MS/MS). This approach allowed the identification of hydroxyl, peroxy, and keto derivatives due to oxidation of unsaturated fatty acyl chains. Oxidation products due to oxidation of serine polar head were also identified. These products, with lower molecular weight than the non-modified PS, were identified as $[\mathrm{M}-29-\mathrm{H}]^{-}$(terminal acetic acid), $\left[\mathrm{M}-30-\mathrm{H}^{-}\right.$(terminal acetamide), $[\mathrm{M}-13-\mathrm{H}]^{-}$(terminal hydroperoxyacetaldehyde), and $[\mathrm{M}-13-\mathrm{H}]^{-}$(terminal hydroxyacetaldehyde plus hydroxy fatty acyl chain). Phosphatidic acid was also formed in these conditions. These findings confirm the oxidation of the serine polar head induced by the hydroxyl radical. The identification of these modifications may be a valuable tool to evaluate phosphatidylserine alteration under physiopathologic conditions and also to help understand the biological role of phosphatidylserine oxidation in the apoptotic process and other biological functions.
\end{abstract}

Key words: Phosphatidylserine, Oxidation, Hydroxyl radical, Electrospray, Mass spectrometry

\section{Introduction}

$\mathrm{P}$ hosphatidylserine (PS) is a phospholipid (PL) that is widely distributed among all mammalian cells. It comprises approximately $10 \%$ of the total phospholipid of the cell and is found preferentially in the inner leaflet of the plasma membrane and in endocytic membranes. PS plays important roles in many biological processes, with emphasis on blood clotting and apoptosis [1]. In some physiologic processes, the asymmetric distribution of phospholipids of

Correspondence to: M. Rosario M. Domingues; e-mail: mrd@ua.pt the plasma membrane is lost and PS is translocated to the outer leaf of the plasma membrane [1-3]. The externalization of PS is an early indicator of apoptosis and is essential for the recognition and removal of apoptotic cell. Phagocytes recognize PS as a signal initiator of apoptosis [1, 4-8]. Tyurina et al. reported that inhibition of aminophospholipid translocase, which selectively pumps phosphatidylserine and phosphatidylethanolamine from the outer to the inner plasma membrane monolayer [9], results in externalization of phosphatidylserine, and activation of macrophages [10]. PS asymmetry has also been associated with clinical situations in which apoptosis plays a relevant role, as in cancer, chronic autoimmunity, and infections [3]. 
Although non-oxidized PS are major ligands recognized by macrophages on the apoptotic cell, there is growing evidence that oxidized PS (oxPS) also can have an active role [1114].

When the phospholipids undergo oxidation, a variety of oxidized products can be formed, mainly due to the modification of unsaturated fatty acyl chains [15]. These modifications can be induced in vivo by enzymatic (cytochrome $c$, myeloperoxidase) or non-enzymatic reactions ( ${ }^{\circ} \mathrm{OOH},{ }^{\circ} \mathrm{OH}, \mathrm{Fe}^{2+}, \mathrm{Cu}^{+}$, radiation). Depending on the predominating oxidative process, different PLs oxidation products can be observed [16]. It is thought that oxidized PLs may have new biological properties, participating in various biological processes such as the immune response, inflammation, apoptosis, and age-related diseases [16]. However, little is known about the relationship between specific oxidation products and their biological effects.

Mass spectrometry (MS) has been used to identify nonoxidized and oxidized phospholipids, including native and oxidized PS [17-21]. PS hydroperoxy and hydroxy species were identified by Kagan and co-authors using electrospray mass spectrometry (ESI-MS) and tandem mass spectrometry (ESI-MS/MS) in negative mode. Oxidized PS has been identified in several pathological conditions: Tyurina et al. identified mono-hydroperoxy derivatives of PS after intestinal injury induced by $\gamma$-irradiation, [22, 23]; Bayir et al. also proposed the presence of PS hydroperoxides derivatives in traumatic brain injury after controlled cortical impact [24]; hydroperoxyl and hydroxyl PS derivates were also identified by Tyurin et al. during apoptosis induced in neurons by staurosporine [25] and in cells and tissues after pro-apoptotic and pro-inflammatory stimuli [26]; the same group showed that the pattern of phospholipid oxidation during apoptosis is non-random and that PS is one of the preferred peroxidation substrates [8].

Although several studies have produced evidence on the role of oxidation of PS in inflammation and apoptosis, there is still insufficient data on the mechanisms of oxidation and on the nature of the oxidized species formed. The objective of this research is to evaluate the molecular changes induced in phosphatidylserines when subjected to oxidative stress, focusing on the oxidation products resulting from oxidation of the polar head. Different PS species were subjected to oxidation induced by the hydroxyl radical generated under Fenton reaction $\left(\mathrm{H}_{2} \mathrm{O}_{2} / \mathrm{Fe}^{2+}\right)$ conditions and the oxidation products were subsequently separated by thin layer chromatography (TLC) and analyzed by electrospray (ESI), mass spectrometry (MS), and tandem mass spectrometry (MS/MS).

\section{Experimental}

\section{Materials}

1-Palmitoyl-2-linoleoyl-sn-glycero-3-phospho-L-serine (PLPS), 1-palmitoyl-2-oleoyl-sn-glycero-3-phospho-L-serine (POPS), 1,2-dipalmitoyl-sn-glycero-3-phospho-L-serine
(DPPS), and palmitoyloleoylphosphatidylethanolamine were obtained from Avanti Polar Lipids, Inc. (Alabaster, AI, USA) and used without further purification. $\mathrm{FeCl}_{2}$, EDTA and $\mathrm{H}_{2} \mathrm{O}_{2}$ $(30 \%, w / w)$ were acquired from Merck (Darmstadt, Germany). Triethylamine (Acros Organics, Geel, Belgium), chloroform (HPLC grade), methanol (HPLC grade). and ethanol absolute (Panreac) were used without further purification. TLC silica gel 60 plates with concentrating zone $(2.5 \times 20 \mathrm{~cm})$ were purchased from Merck.

\section{Oxidation of Phosphatidylserine by Fenton Reaction}

Ammonium hydrogen carbonate buffer $(5 \mathrm{mM}, \mathrm{pH} 7.4)$ was added to $1 \mathrm{mg}$ of phospholipid $(2 \mathrm{mg} / \mathrm{mL})$ and the solution was vortex-mixed and sonicated for the formation of vesicles. Oxidative treatments using $\mathrm{Fe}$ (II) and $\mathrm{H}_{2} \mathrm{O}_{2}$ were carried out by adding $40 \mu \mathrm{M} \mathrm{FeCl}_{2}$ /EDTA (1:1) and $10 \mathrm{mM}$ of $\mathrm{H}_{2} \mathrm{O}_{2}$ to total a volume of $500 \mu \mathrm{L}$ of solution. The mixture was left to react at $37{ }^{\circ} \mathrm{C}$ in the dark for several days with agitation. Controls were performed by replacing $\mathrm{H}_{2} \mathrm{O}_{2}$ with water and without $\mathrm{H}_{2} \mathrm{O}_{2}$ and $\mathrm{Fe}^{2+}$.

\section{ESI-MS Conditions (Linear Ion Trap)}

The extent of oxidation was monitored by electrospray mass spectrometry in a linear ion trap mass spectrometer LXQ (ThermoFinnigan, San Jose, CA, USA). The LXQ linear ion trap mass spectrometer was operated in negative mode. ESI conditions were as follows: electrospray voltage was $4.7 \mathrm{kV}$; capillary temperature was $275^{\circ} \mathrm{C}$, and the sheath gas flow was $25 \mathrm{U}$. An isolation width of $0.5 \mathrm{Da}$ was used with a $30 \mathrm{~ms}$ activation time for MS/MS experiments. Full scan MS spectra and MS/MS spectra were acquired with a $50 \mathrm{~ms}$ and $200 \mathrm{~ms}$ maximum ionization time, respectively. For MS/MS experiments, normalized collision energy (CE) was applied in the range of 17 to 20 (arbitrary units) for MS/MS. Data acquisition was carried out on an Xcalibur data system (ver. 2.0).

\section{Exact Mass Measurement and Elemental Composition}

Identification of the oxidation product ions corresponding to the oxidation in the polar head group was confirmed by exact mass measurement and elemental composition determination in a MALDI-TOF/TOF mass spectrometer. Elemental composition of the ion at $\mathrm{m} / \mathrm{z} 721.5$ (observed for DPPS) was confirmed by exact mass measurement and elemental composition determination using a ESI-Q-TOF2 mass spectrometer due to the presence of a contaminate with the same $\mathrm{m} / \mathrm{z}$ value in the MALDI-MS spectrum.

\section{MALDI-MS Conditions}

MALDI mass spectra were acquired using a MALDI-TOF/ TOF Applied Biosystems 4800 Proteomics Analyzer 
(Applied Biosystems, Framingham, MA, USA) instrument equipped with a nitrogen laser emitting at $337 \mathrm{~nm}$ and operating in a reflectron mode. Full scan mass spectra ranging from $\mathrm{m} / \mathrm{z} 650$ to 4000 were acquired in the negative mode. All spectra were acquired with 2,5-dihydroxybenzoic acid (DHB) matrix. The matrix solution was prepared by dissolving $10 \mathrm{mg}$ of DHB in a $1 \mathrm{~mL}$ mixture of methanol: aqueous $(1: 1, \mathrm{vol} / \mathrm{vol})$. For the accurate mass measurements, the lock mass in each mass spectrum was the calculated monoisotopic mass/charge of the non-modified phosphatidylserine and palmitoyloleoylphosphatidylethanolamine as internal standard.

\section{ESI-MS Conditions (ESI-Q-TOF2)}

For the analysis in the ESI-QTOF2 instrument (Micromass, Manchester, UK), the flow rate was $10 \mu \mathrm{L} \mathrm{min}^{-1}$, the needle voltage was set at $3 \mathrm{kV}$, the cone voltage at $30 \mathrm{~V}$, the ion source set at $80^{\circ} \mathrm{C}$, and the desolvation temperature at $150{ }^{\circ} \mathrm{C}$. Mass spectra were averaged for $1 \mathrm{~min}$. For the accurate mass measurements, the lock mass in each mass spectrum was the calculated monoisotopic mass/charge of the native phospholipid (non-modified phospholipid).

\section{Separation of Oxidation Products of PS by Thin Layer Chromatography}

The oxidation products were separated by thin layer chromatography (TLC) using silica gel 60 plates with concentrating zone $2.5 \times 20 \mathrm{~cm}$ (Merck KGaA). Prior to separation, plates were treated with boric acid $2.3 \%$ in ethanol. The plates were developed with solvent mixture chloroform/ethanol/water/triethylamine (30:35:7:35, vol/vol/ $\mathrm{vol} / \mathrm{vol})$. Lipid spots on TLC plates were observed by exposure to primuline. The TLC spots identified as oxidized PS were scraped from the plates and extracted using chloroform/methanol $(2: 1, \mathrm{vol} / \mathrm{vol})$. The oxidation products separated by thin layer chromatography (TLC) were analyzed by electrospray (ESI), mass spectrometry (MS), and tandem mass spectrometry (MS/MS).

\section{Results and Discussion}

This paper focuses on the ESI-MS analysis of PS that was submitted to oxidation induced by the hydroxyl radical generated under Fenton reaction $\left(\mathrm{H}_{2} \mathrm{O}_{2} / \mathrm{Fe}^{2+}\right)$. Selected PS were dipalmitoyl-phosphatidylserine (DPPS; C16:0/C16:0; $\left.m / z[\mathrm{M}-\mathrm{H}]^{-}=734\right)$, 1-palmitoyl-2-oleoyl-phosphatidylserine (POPS; $\mathrm{C} 16: 0 / \mathrm{C} 18: 1 ; \mathrm{m} / z[\mathrm{M}-\mathrm{H}]^{-}=758$ ), and the 1palmitoyl-2-linoleoyl phosphatidylserine (PLPS; C16:0/ $\mathrm{C} 18: 2 ; m / z[\mathrm{M}-\mathrm{H}]^{-}=756$ ) (Figure 1). Since DPPS contains saturated acyl chains, it is considered as a model for studying oxidation of the phospholipid polar head [15].

Comparing the ESI-MS spectra of the three PS obtained before and after oxidation (Figure 2), new ions can be observed. These ions correspond to the $[\mathrm{M}-\mathrm{H}]^{-}$molecular ions of oxidation products. The ESI-MS spectra of PLPS (Figure 2a), acquired after exposure to oxidative conditions, show a larger number of new molecular ions. This is due to the presence in this molecule of two double bonds in the $s n$ 2 fatty acyl chain, increasing the number of possible oxidation sites. Lower number of ions were observed for POPS (Figure 2c) and even lower for DPPS (Figure 2e). In the spectra of oxPLPS and oxPOPS, some oxidation products can be observed at higher $\mathrm{m} / \mathrm{z}$ values than the non-modified PS, corresponding to the oxidation products with insertion of oxygen atoms as hydroperoxides $([\mathrm{M}-\mathrm{H}+$ $\left.2 \mathrm{O}]^{-}\right)$, hydroxide $\left(\left[\mathrm{M}-\mathrm{H}+\mathrm{O}^{-}\right)\right.$, and keto $([\mathrm{M}-\mathrm{H}+\mathrm{O}-$ $2 \mathrm{Da}]^{-}$) derivatives. These oxidation products will be briefly discussed in this work since they have already been described and fully characterized [13, 23, 25].

In the spectrum obtained after oxidation of the PLPS (Figure 2a) we can observe new ions at $m / z 666$ and 682 $(666+16)$, with lower $\mathrm{m} / \mathrm{z}$ than the non-modified PLPS. These ions correspond to oxidation products with shortened acyl chain at C9 and a carboxylic acid terminal. Short chain oxidation products originated from cleavage of fatty acyl chains have been described for PS [13] and have been studied in phosphatidylcholine, phosphatidylserine, and cardiolipin phospholipids [27-29]. The shortened oxidation products are generated after abstraction of the bis-allylic hydrogen atoms by the hydroxyl radical, which through a $\beta$ scission mechanism, break down to short-chain phospholipid products with terminal aldehydic or carboxylic acid function. As reviewed elsewhere, these are well known products of lipid peroxidation [30, 31]. No short chain oxidation products were formed during POPS oxidation, similar to previously observed POPC oxidation, using the same oxidative conditions [31].

There are other ions observed at lower $\mathrm{m} / \mathrm{z}$ than the nonmodified PS in MS spectra of oxidized PLPS, POPS, and DPPS (Figure 2a, c, and e), which were not assigned as shortchain compounds. These oxidation products, with less 29, 30, and 13 Da compared with the native PS, occur due to oxidative modification in PS polar head, as confirmed by separation using thin layer chromatography (TLC) (Figure 3), and analysis by tandem mass spectrometry will be described latter. Elemental composition determination for the ions with less $29 \mathrm{Da}$ (for DPPS: $\mathrm{C}_{37} \mathrm{H}_{70} \mathrm{O}_{10} \mathrm{P}$, error $18.7 \mathrm{ppm}$; for POPS $\mathrm{C}_{39} \mathrm{H}_{72} \mathrm{O}_{10} \mathrm{P}$, error $27.8 \mathrm{ppm}$, for PLPS $\mathrm{C}_{39} \mathrm{H}_{70} \mathrm{O}_{10} \mathrm{P}$, error $-15.4 \mathrm{ppm}$ ), with less $30 \mathrm{Da}$ (for DPPS, $\mathrm{C}_{37} \mathrm{H}_{71} \mathrm{NO}_{9} \mathrm{P}$ error $10.3 \mathrm{ppm}$; for POPS $\mathrm{C}_{39} \mathrm{H}_{73} \mathrm{NO}_{9} \mathrm{P}$, error $-1.3 \mathrm{ppm}$; for PLPS $\mathrm{C}_{39} \mathrm{H}_{71} \mathrm{NO}_{9} \mathrm{P}$ error $-32.1 \mathrm{ppm}$ ), and with less $13 \mathrm{Da}$ (for DPPS $\mathrm{C}_{37} \mathrm{H}_{70} \mathrm{O}_{11} \mathrm{P}$ error -9.9; for POPS $\mathrm{C}_{39} \mathrm{H}_{72} \mathrm{O}_{11} \mathrm{P}$ error $20.9 \mathrm{ppm}$ ) confirmed the modification of serine polar head.

Mass spectrometry analysis, in positive mode, of these oxidized PS, showed molecular ions that correspond to the same oxidation products, but observed as low abundant $[\mathrm{M}+$ $\mathrm{H}]^{+},[\mathrm{M}+\mathrm{Na}]^{+}$, and $[\mathrm{M}-\mathrm{H}+2 \mathrm{Na}]^{+}$ions (data not shown). However, the oxidation product resulting from loss of $29 \mathrm{Da}$ was not observed. We propose that this oxidation product contains a carboxylic acid group polar head, as will be 


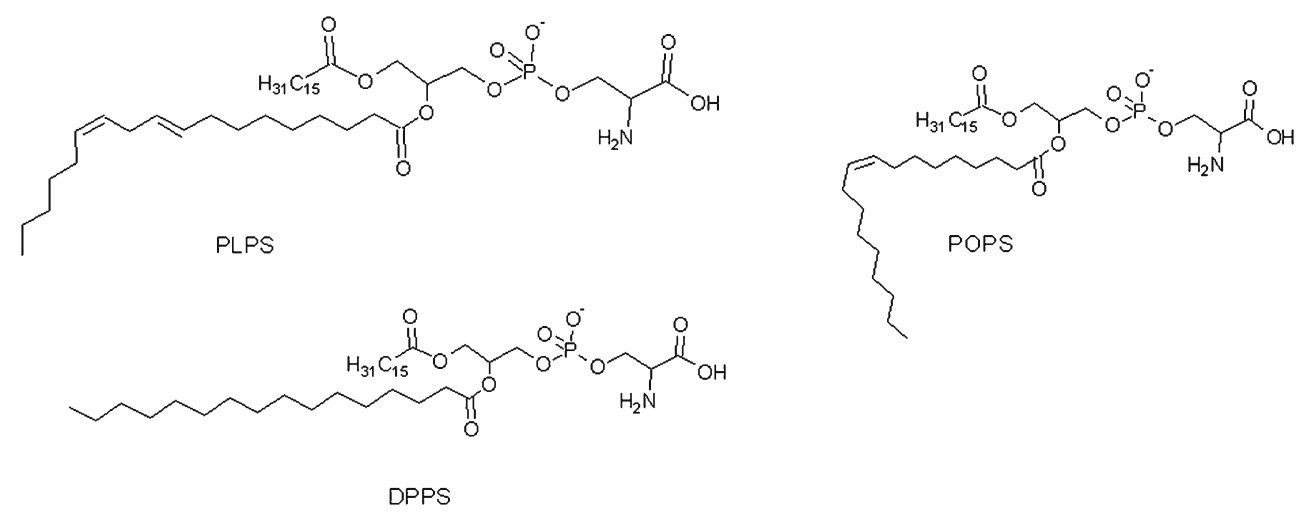

Figure 1. Molecular structures of PLPS, POPS, and DPPS

described latter, forming, preferentially, negative ions. To better characterize these new oxidation products, they were further analyzed by TLC, MS, and MS/MS in negative mode.

\section{Phosphatidylserine Oxidation in Fatty Acyl Chains-Analysis by ESI-MS/MS}

Hydroperoxide and hydroxide derivatives are primary oxidation products of lipids and phospholipids, and occur during PLPS and POPS oxidation. DPPS does not yield these oxidation products because it has two saturated fatty acyl chains that do not oxidize [15]. ESI-MS/MS spectra of PLPS and POPS oxidation products show formation of hydroxy [M $-\mathrm{H}+\mathrm{O}^{-}$, keto $[\mathrm{M}-\mathrm{H}+\mathrm{O}-2 \mathrm{Da}]^{-}$, peroxy $[\mathrm{M}-\mathrm{H}+2 \mathrm{O}]^{-}$, and hydroxy peroxy $[\mathrm{M}-\mathrm{H}+3 \mathrm{O}]^{-}$derivatives, as summarized in Table 1. In all these MS/MS spectra, we can observe a major product ion formed by loss of $87 \mathrm{Da}$, due to loss of phospholipid polar head. This is an abundant loss, typical of PS [18]. MS/MS analysis (Table 1) shows that insertion of oxygen atoms occur in the linoleic (for PLPS) or (a)

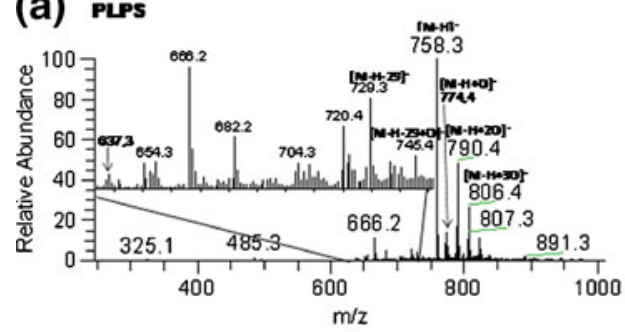

(c)

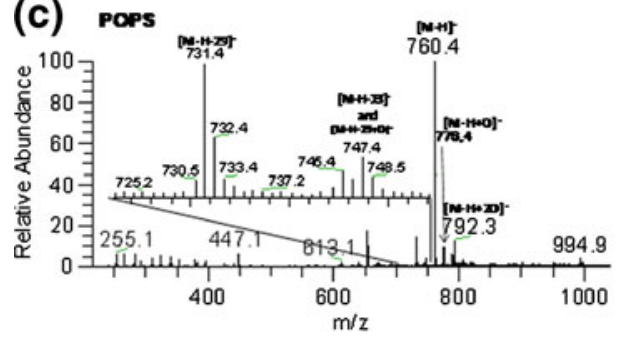

(e)

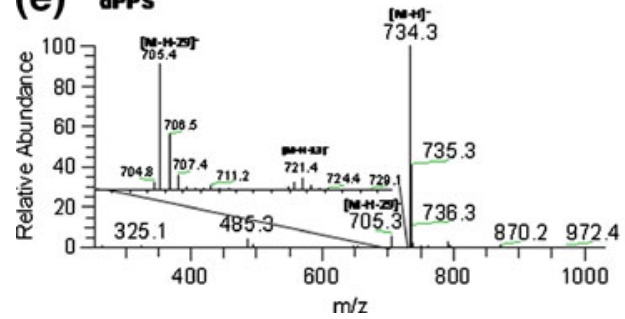

(b)

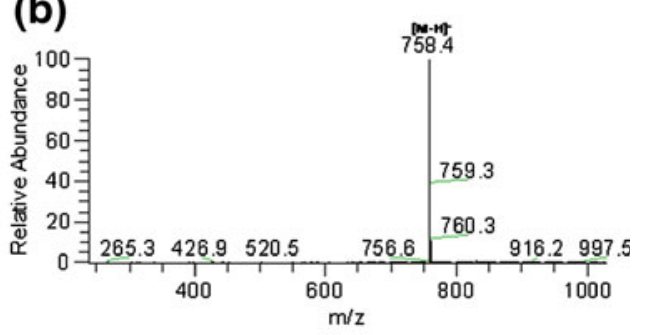

(d)
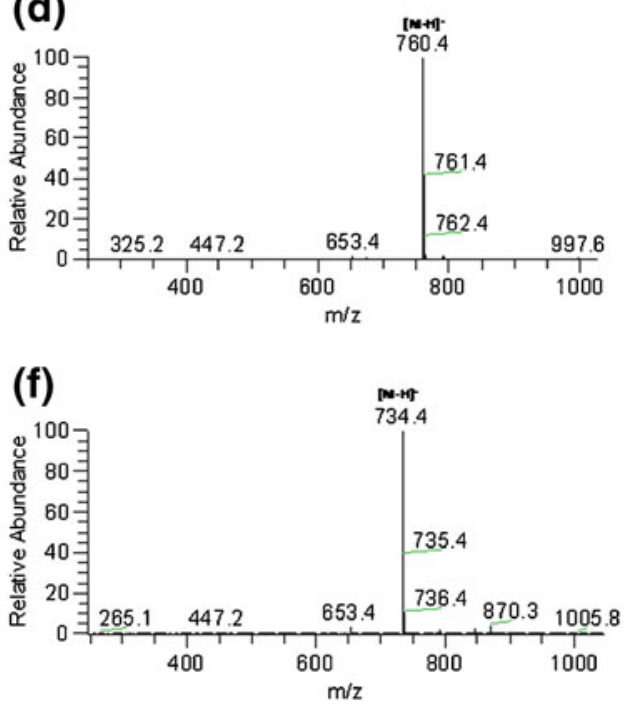

Figure 2. ESI-MS spectra of PLPS (a), (b), POPS (c), (d) and DPPS (e), (f). Spectra a, c, and e were acquired after exposing samples to oxidative stress. Spectra $b, d$, and $f$ were acquired from control samples 


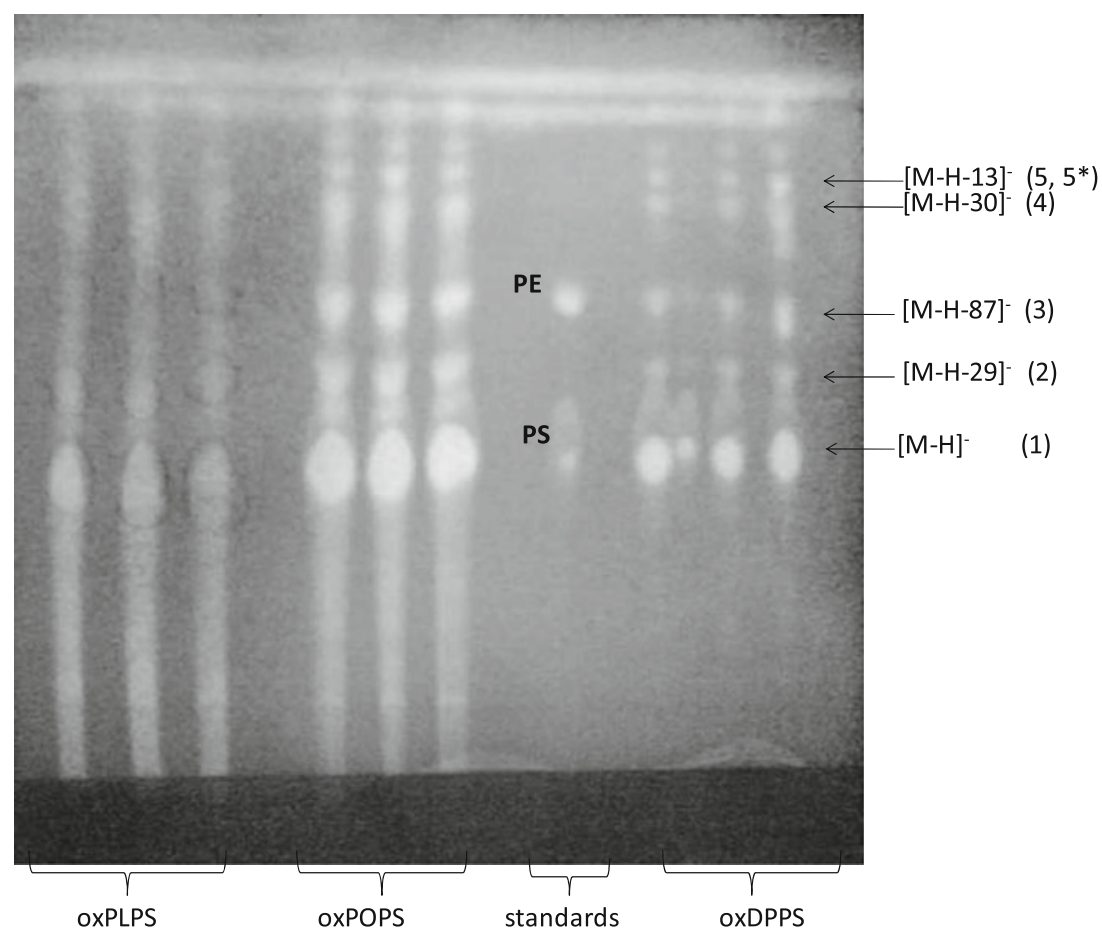

Figure 3. TLC of oxidation products of phosphatidylserines with modifications in the polar head (oxPLPS (lines 1, 2, and 3), oxPOPS (lines 4, 5, and 6), and oxDPPS (lines 8, 9, and 10). PS and PE standards were applied in line 7

oleic acids (for PLPS), as confirmed by the observation of the carboxylate anions of modified fatty acyl chains $\mathrm{R}^{\prime} \mathrm{COO}^{-}$, in agreement with previous published work [26, 28, 31-33].

\section{Phosphatidylserine Oxidation with Modification of in Polar Head-Analysis by TLC and ESI-MS/ $M S$}

Oxidative modifications in the PS polar head should change significantly the polarity of these species. Consequently, their separation may be possible through simple techniques such as TLC, which is widely used for separation of different classes of phospholipids. Thus, oxidative mixtures of the three PS under study were fractioned by TLC, as is illustrated in Figure 3.

Table 1. Product Ions Observed in ESI-MS/MS Spectra of Oxidized PLPS and POPS, which were Determined by Tandem Mass Spectrometry to Contain Modified Fatty Acyl Chains

\begin{tabular}{llcccc}
\hline & \multicolumn{2}{l}{ Modifications } & {$[\mathrm{M}-\mathrm{H}]^{-}$} & $\mathrm{R}_{2}{ }^{\prime} \mathrm{COO}^{-}$ & {$\left[\mathrm{M}-\mathrm{R}_{1} \mathrm{COOH}-87-\mathrm{H}\right]^{-}$} \\
\cline { 2 - 5 } PLPS & +1 O & $-\mathrm{OH}$ & 774 & 295 & 431 \\
& & $-=\mathrm{O}$ & 772 & 293 & 429 \\
& +2 O & 790 & 311 & 447 \\
& +3 O & 806 & 327 & 463 \\
& Short (C9)* & 666 & 187 & 323 \\
& Short (C9) + O & 682 & 203 & 339 \\
POPS & +1 O & 776 & 297 & 433 \\
& & 774 & 295 & 431 \\
\multirow{2}{*}{ DPPS } & +2 O & 792 & 313 & 449 \\
\hline
\end{tabular}

*Short chain oxidation product in $\mathrm{C} 9$ with carboxylic acid terminal.
In the TLC of the oxidized PS, five new spots were resolved using the same conditions used to separate phospholipid classes, demonstrating that significant changes of polarity have occurred, presumably with formation of new compounds with different polar head structures. The new spots were scraped from the plate, the OxPL extracted, and further analyzed by ESI-MS and MS/MS. Table 2 summarizes are all molecular ions observed in MS spectra for each spot of TLC and the proposed structure.

In spots \#1 (Figure 3, Table 2) we have identified the non-modified PS together with the hydroperoxides, keto, and hydroxides oxidation products (Table 1), in agreement with previous results [26]. In the spots \#2 (Figure 3, Table 2) we identified, for all PS, oxidation products with polar head modifications $[\mathrm{M}-\mathrm{H}-29]^{-}$. Spots \#3 (Figure 3, Table 2) shows a Rf similar to the phosphatidic acid (PA) standard. The MS spectra acquired from samples of these spots show $[\mathrm{M}-\mathrm{H}-87]^{-}$ions, thus indicating that PA is generated during PS oxidation, with complete loss of polar head. PA was also observed during cardiolipin oxidation by $\gamma$ irradiation [34, 35]. The oxidation products from spots \#4 (Figure 3, Table 2) contained a head modification, with a mass difference of less $30 \mathrm{Da}$. It is also possible to observe spots \#5 (Figure 3, Table 2) in the DPPS and POPS. Analysis of the MS spectrum of these samples shows the presence of ions at $m / z 747$ and 763 for POPS, and an ion at $\mathrm{m} / \mathrm{z} 721$ for DPPS. These ions have a difference of $13 \mathrm{Da}$ compared with the non-modified PS. In the case of PLPS, these oxidation products were not observed, probably because they might decompose to fatty acyl short chain 
Table 2. Molecular Ions Observed in the ESI-MS Spectra from the Different Spots Identified in the TLC Plate for Each PS. The Table Shows the $m / z$ Value of the $[\mathrm{M}-\mathrm{H}]^{-}$Ions, their Most Probable Identification, Including the Modified Polar Headgroup, and the Typical Neutral Loss, Observed in the MS/MS Spectra

\begin{tabular}{|c|c|c|c|c|c|c|}
\hline \multirow{2}{*}{$\begin{array}{c}\text { Spots } \\
\#\end{array}$} & \multirow{2}{*}{ Modification } & \multicolumn{3}{|c|}{$[\mathrm{M}-\mathrm{H}]^{-}$} & \multirow{2}{*}{$\begin{array}{l}\text { Polar } \\
\text { head }\end{array}$} & \multirow{2}{*}{$\begin{array}{c}\text { Neutral } \\
\text { loss }\end{array}$} \\
\hline & & PLPS & POPS & DPPS & & \\
\hline \multirow{7}{*}{1} & - & 758 & 760 & 734 & \multirow{7}{*}{$-\mathrm{H}_{2} \mathrm{C}-\mathrm{CO}^{\mathrm{CO}}$} & \multirow{7}{*}{87} \\
\hline & +14 & 772 & 774 & - & & \\
\hline & +16 & 774 & 776 & - & & \\
\hline & +30 & 788 & 790 & - & & \\
\hline & +32 & 790 & 792 & - & & \\
\hline & +46 & 804 & - & - & & \\
\hline & +48 & 806 & - & - & & \\
\hline \multirow{5}{*}{2} & -29 & 729 & 731 & 705 & \multirow{5}{*}{$-\mathrm{H}_{2} \mathrm{C}-\mathrm{O}_{\mathrm{O}}^{\mathrm{O}}$} & \multirow{5}{*}{58} \\
\hline & $-29+14$ & 743 & 745 & - & & \\
\hline & $-29+16$ & 745 & 747 & - & & \\
\hline & $-29+30$ & 759 & 761 & - & & \\
\hline & $-29+32$ & 761 & 763 & - & & \\
\hline \multirow{5}{*}{3} & -87 & 671 & 673 & 647 & \multirow{5}{*}{ absent } & \multirow{5}{*}{-} \\
\hline & $-87+14$ & 685 & 687 & - & & \\
\hline & $-87+16$ & 687 & 689 & - & & \\
\hline & $-87+30$ & 701 & 703 & - & & \\
\hline & $-87+32$ & 703 & 705 & - & & \\
\hline \multirow{5}{*}{4} & -30 & 728 & 730 & 704 & \multirow{5}{*}{$-\mathrm{H}_{2} \mathrm{C}-{ }_{\mathrm{NH}}^{\mathrm{O}}$} & \multirow{5}{*}{57} \\
\hline & $-30+14$ & 742 & 744 & - & & \\
\hline & $-30+16$ & 744 & 746 & - & & \\
\hline & $-30+30$ & 758 & 760 & - & & \\
\hline & $-30+32$ & 760 & 762 & - & & \\
\hline \multirow{2}{*}{5} & -13 & - & 747 & 721 & & \multirow{2}{*}{74} \\
\hline & $-13+16$ & - & 763 & - & & \\
\hline $5^{\star}$ & -13 & & 747 & & & 58 \\
\hline
\end{tabular}

derivatives, which are not observed in TLC plate. The MS spectra of POPS samples from spots \#5 show ions at the same $\mathrm{m} / \mathrm{z}$ of ions found in spots \#2. These are necessarily different compounds, since they have different Rf. The nature of these ions was determined by MS/MS analysis and will be discussed in another section of this manuscript. In each spot of PLPS and POPS oxidized samples, additional ions with plus $14 \mathrm{Da}(+\mathrm{O}-2 \mathrm{Da}), 16 \mathrm{Da}(+\mathrm{O}), 30 \mathrm{Da}(+2 \mathrm{O}$ $-2 \mathrm{Da}), 32 \mathrm{Da}(+2 \mathrm{O}) 46 \mathrm{Da}(+3 \mathrm{O}-2 \mathrm{Da})$, and $48 \mathrm{Da}(+3 \mathrm{O})$ were observed. These ions resulted from additional oxidation in unsaturated fatty acyl chain, as is shown in Table 2.

In order to confirm the structure of the oxidation products found in spots $\# 2$ to $\# 5$, MS/MS of all the identified molecular ions (Table 2) were obtained and analyzed. These spots corresponded to oxidation products resulting from modification of PS polar head.

The oxidation products with less $29 \mathrm{Da}$ than the unoxidized PS, found in spots \#2, show a neutral loss of $58 \mathrm{Da}$, instead of the typical $87 \mathrm{Da}$ of PS (Figure 4). The MS/MS of these ions $[\mathrm{M}-\mathrm{H}-29]^{-}$show the non-modified carboxylate anions $\mathrm{RCOO}^{-}$, thus confirming that the structural changes occurred at the polar head and not at the fatty acyl chains. This main fragmentation pathway (loss of
$58 \mathrm{Da}$ ) is also observed for the oxidation products with additional oxidation $(+\mathrm{nO})$ in the unsaturated fatty acyl chains observed for PLPS and POPS. Tandem mass spectra of these ions also showed the modified $\mathrm{RCOO}^{-}$. Oxidation products with less $29 \mathrm{Da}$ were observed during the oxidation of amino acids and were identified as the result of oxidative reactions that lead to loss of an amine group and $\mathrm{CO}_{2}$, with formation of a terminal carboxylic acid group [36]. We propose that oxidation products observed in spots \#2 are glycerophosphoaceticacid derivatives (Scheme 1).

The new oxidation products identified in spots \#3 are due to oxidation in polar head group of the PS. These oxidative modifications are not observable when a neutral loss scan of aziridine-2-carboxylic acid (neutral loss of $87 \mathrm{Da}$ ) is performed to detect oxidized PS from in vivo samples [13].

The MS/MS spectra of molecular ions $[\mathrm{M}-\mathrm{H}-30]^{-}$ found in spots \#4 of the three PS show loss of the head group as loss of $57 \mathrm{Da}$, but typical loss of $87 \mathrm{Da}$ is not observed. We propose that these oxidation products resulted from decarboxylation and generation of a keto moiety, as observed during amino acid and peptides oxidation (Scheme 1) [36]. In these species, loss of modified polar head group $(-57 \mathrm{Da})$ is not the base peak of the spectra, in 

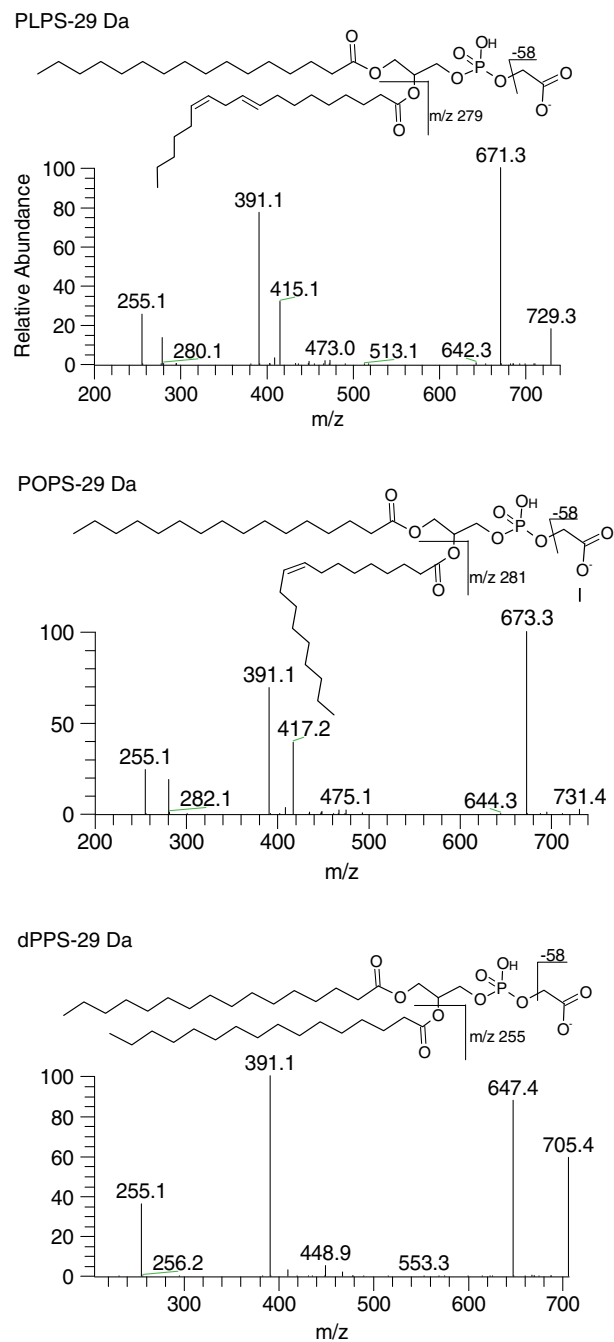
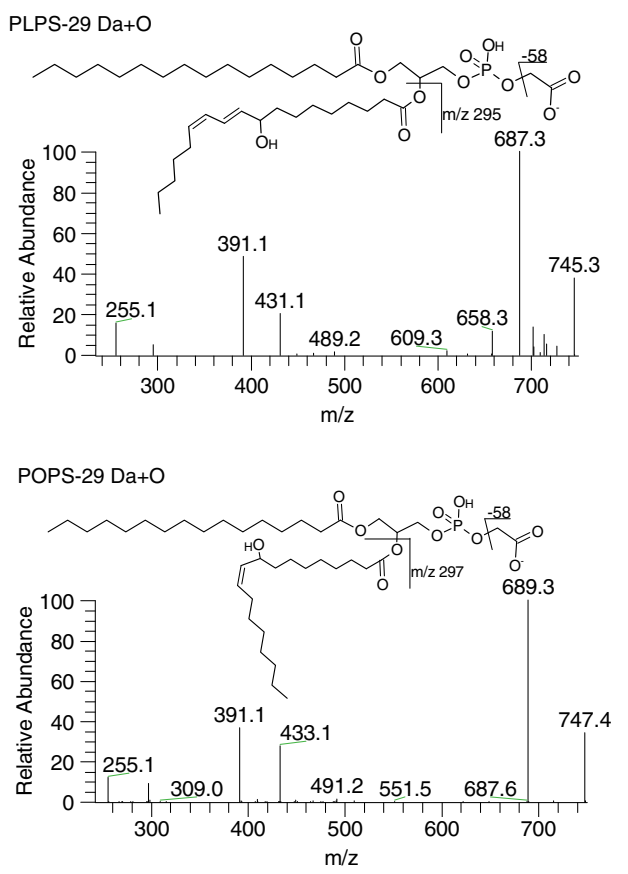

Figure 4. ESI-M/MS spectra of [M $-\mathrm{H}-29]^{-}$molecular ions that resulted from oxidation of PLPS $(\mathrm{m} / z 729$ and 745$)$, POPS $(\mathrm{m} / \mathrm{z}$ 731 and 747 ), and DPPS ( $\mathrm{m} / \mathrm{z} 705)$, found in spots \#2. The proposed structures of each molecular ion are also shown. The structures of the oxidation products PLPS $-29 \mathrm{Da}+\mathrm{O}$ and POPS $-29 \mathrm{Da}+\mathrm{O}$ illustrate one possible location of the hydroxyl group in the unsaturated fatty acyl chains

contrast with the typical behavior of PS and the other identified PS oxidation products. A minor loss of polar head group resembles the behavior observed in negative mode tandem mass spectra of PE. Also, as observed in PE tandem mass spectra, $\mathrm{R}_{1} \mathrm{COO}^{-}$ions were found to be more abundant than $\mathrm{R}_{2} \mathrm{COO}^{-}$ions. This is in contrast with the typical behavior of PS and other oxidation products with a terminal carboxylic acid function, which show in their MS/MS spectra that RA of $\mathrm{R}_{2} \mathrm{COO}^{-}>\mathrm{R}_{1} \mathrm{COO}^{-}$[37]. These findings also contributed to proposing the presence of a free amine moiety in these oxidation products (M-30 Da). We propose that oxidation products observed in spots \#3 are glycerophosphoacetamide derivatives (Scheme 1) (Figure 5).

The MS/MS spectra of $[\mathrm{M}-\mathrm{H}-13 \mathrm{Da}]^{-}$molecular ions that resulted from oxidation of DPPS and POPS (Figure 6) and were found in spots \#5 (Table 2), are very similar. In these spectra, we observe a major fragment ion formed by loss of $32 \mathrm{Da}\left(-\mathrm{O}_{2}\right)$, indicating the presence of a hydroperoxide $[28,38]$. Due to the fact that DPPS does not oxidize in the fatty acyl chain, the hydroperoxide moiety should be located in polar head group. We propose that these oxidation products resulted from oxidation in the polar head group, with formation of terminal hydroperoxydeacetaldehyde, as shown in Table 2. The presence of a modified polar head group is also evidenced by the presence of carboxylate anions of the non-modified fatty acyl chains in the MS/MS spectra and the observation of a neutral loss of $74 \mathrm{Da}$ (hydroperoxydeacetaldehyde). The MS/MS spectra of POPS $\left(\mathrm{m} / \mathrm{z}\right.$ 747) found in spots \# $5^{*}$ also shows oleoyl carboxylate anion $+16(\mathrm{~m} / z 297)$ and loss of $58 \mathrm{Da}\left(\mathrm{CH}_{2}(\mathrm{OH}) \mathrm{HC}=\mathrm{O}\right)$. This suggests the presence of an isobar originated by oxidation of the polar head group, with formation of a 
$\mathrm{R}_{1}-\mathrm{C}_{15} \mathrm{H}_{31}$
$\mathrm{R}_{2}-\mathrm{C}_{15} \mathrm{H}_{31} ; \mathrm{C}_{17} \mathrm{H}_{33} ; \mathrm{C}_{17} \mathrm{H}_{31}$<smiles>[R]C(=O)OC[C@@H](COP(=O)(OC)OC[C@H](N)C(=O)O)OC([R])=O</smiles>

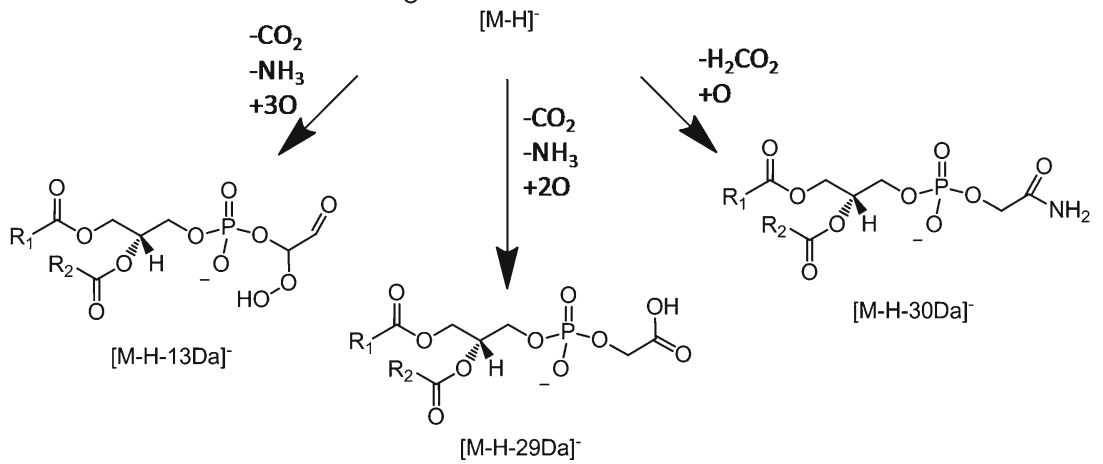

Scheme 1. Oxidation products of PS formed by Fenton reaction with observed modifications on the polar head group: terminal hydroperoxyacetaldehyde (-13 Da), terminal acetic acid (-29 Da), and terminal acetamide (-30 Da)
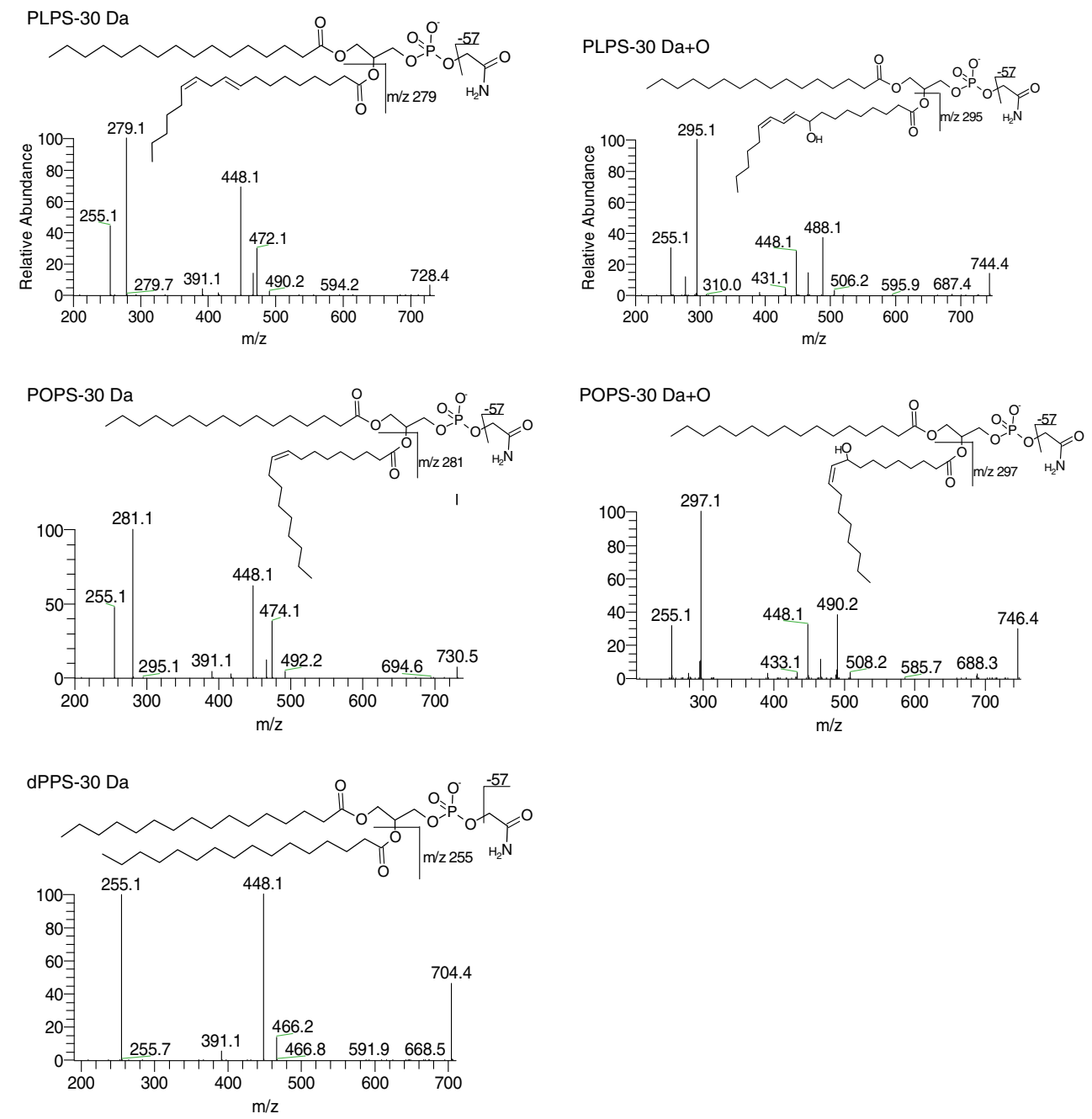

Figure 5. ESI - MS/MS spectra of [M - H - 30] $]^{-}$ions that resulted from oxidation of PLPS, POPS and DPPS, found in spots \#4. The proposed structures of each molecular ion are also shown 
(a)
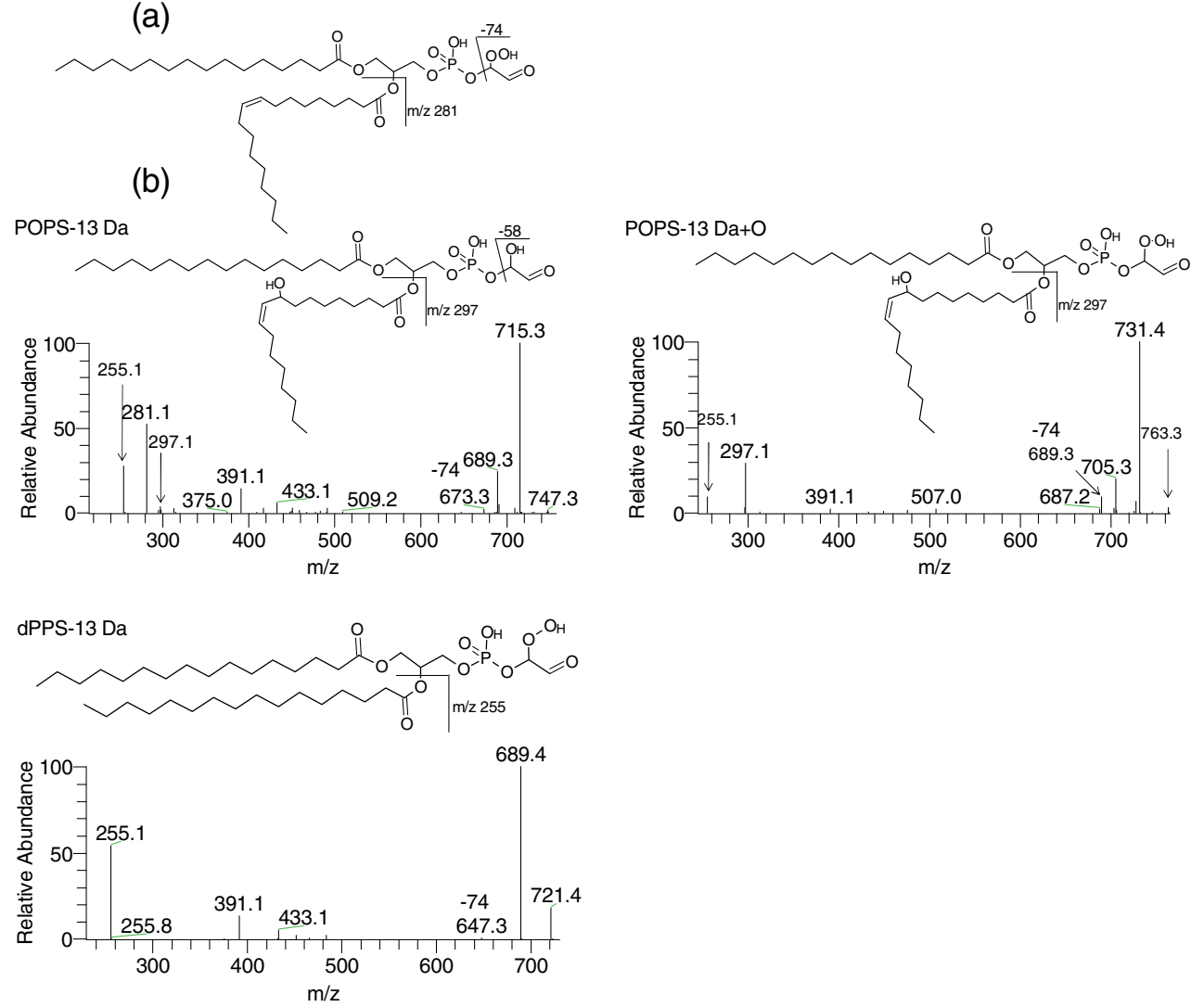

Figure 6. ESI-M/MS spectra of the [M - H - 13] $]^{-}$ions that resulted from oxidation of POPS $(\mathrm{m} / z 747$ and 763$)$ and DPPS $(\mathrm{m} / \mathrm{z}$ 721), found in spots \#5. The proposed structures of each molecular ion are also shown

species containing a terminal hydroxyacetaldehyde, and a hydroxylated acyl chain (Figure 6a). The ion at $\mathrm{m} / \mathrm{z} 763$, observed in POPS spots \#5, corresponds to a species with a hydroperoxydeacetaldehyde polar and a hydroxylated acyl chain, as suggested by the fragment ion at $\mathrm{m} / \mathrm{z} 297[\mathrm{RCOO}+$ $\mathrm{O}^{-}$and a neutral loss $74 \mathrm{Da}$ (Figure 6b).

Phosphatidylserine polar head group has a serine amino acid moiety linked to the phosphate group It is well known that amino acids are prone to oxidation, not only in the side chains but also in the alfa carbon [36, 39, 40]. Oxidative modification of the PS polar head group has been reported to occur during oxidation induced by $\mathrm{HClO}$ and catalyzed by myeloperoxidase $[41,42]$, confirming the reactivity of serine under oxidative conditions. The oxidation products reported to be formed in those conditions were not the same as the ones reported in this work. In those works, the authors reported the formation of 1,2dipalmitoyl-sn-glycero-3-phosphoacetaldehyde and 1,2dipalmitoyl-sn-glycerol-3-phosphonitrile derivatives.

The changes of the serine polar head group induced by the hydroxyl radical resemble the oxidative modifications of the amino acid structure, such as the oxidative decarboxylation with formation of an additional keto group (oxidation products with $-30 \mathrm{Da}$ ). Decarboxylation of amino acids is a well-known reaction occurring during amino acid and peptide oxidation. Loss of $\mathrm{CO}_{2}$ from the $\mathrm{C}$ terminal is due to $\beta$-scission of an alkoxyl radical at the $\mathrm{C}$ terminal alpha carbon. This reaction is proposed to be initiated from the abstraction of hydrogen linked to an alfa carbon, generating a tertiary radical that is stabilized by the amine nitrogen and carbonyl group [40, 43].

The modification in the PS polar head group leading to the formation of the oxidation products with less $29 \mathrm{Da}$ should occur by decarboxylation plus deamination with formation of a terminal carboxylic acid moiety (oxidation products with $-29 \mathrm{Da}$ ). Loss of amine and $\mathrm{CO}_{2}$ resembles typical modification already observed during amino acid oxidation, as reviewed elsewhere [36, 39].

\section{Conclusions}

Oxidative modifications induced to phosphatidylserine were identified and characterized by thin layer chromatography combined with tandem mass spectrometry. Oxidation products were fractionated by TLC and further characterized by MS/MS. This approach allowed the identification of hydroxyl, peroxy, and keto derivatives due to oxidation of unsaturated fatty acyl chains. Additionally, we have identified for the first time five families of oxidation products, with lower molecular weight than the non-modified PS, which resulted from oxidative modifications on the serine polar head group. They were identified as $[\mathrm{M}-29-\mathrm{H}]^{-}$ 
(terminal acetic acid), $[\mathrm{M}-30-\mathrm{H}]^{-}$(terminal acetamide), $[\mathrm{M}-13-\mathrm{H}]^{-}$(terminal hydroperoxideacetaldehyde), and $[\mathrm{M}-29-\mathrm{H}]^{-}$(terminal hydroxyacetaldehyde). Phosphatidic acid derivatives were also formed as result of PE oxidation. Hydroxy, keto, peroxy, and short chain acyl derivatives of these new molecules were also identified for PS phospholipids with unsaturated fatty acyl chains.

The results presented here allowed the identification, for the first time, of modification of PS polar head group induced by the hydroxyl radical mediated oxidation in vitro conditions. The identification of oxidation products of PS is far from being completely explored, although it is essential to understanding the relation between the PS oxidation products formed and the specific biological activity that they mediate.

\section{Acknowledgments}

The authors acknowledge Fundação para a Ciência e a Tecnologia and COMPTE for funding of projects PTDC/ QUI- BIQ/104968/2008, REDE/1504/REM/2005 (that concerns the Portuguese Mass Spectrometry Network) and Ph.D. grants to E.M. (SFRH/BD/73203/2010) and to C. S. (SFRH/ $\mathrm{BD} / 46293 / 2008)$.

\section{References}

1. Leventis, A., Grinstein, S.: The Distribution and Function of Phosphatidylserine in Cellular Membranes. Annu. Rev. Biophys. 39, 407-427 (2010)

2. Divittorio, K.M., Lambert, T.N., Smith, B.D.: Steroid-derived phospholipid scramblases induce exposure of phosphatidylserine on the surface of red blood cells. Bioorg. Med. Chem. 13(14), 4485-4490 (2005)

3. Chaurio, R.A., Janko, C., Munoz, L.E.: Phospholipids: Key players in apoptosis and immune regulation. Molecules 14, 4892-4914 (2009)

4. Fadeel, B., Xue, D., Kagan, V.: Programmed cell clearance: Molecular regulation of the elimination of apoptotic cell corpses and its role in the resolution of inflammation. Biochem. Biophys. Res. Commun. 396, 7$10(2010)$

5. De Jong, K., Larkin, S.K., Styles, L.A., Bookchin, R.M., Kuypers, F.A.: Characterization of the phosphatidylserine-exposing subpopulation of sickle cells. Blood 98(3), 860-867 (2001)

6. Fadeel, B., Quinn, Xue, D., Kagan, V.: Fat(al) attraction: Oxidized lipids act as "eat-me" signals. HFSP J. 1(4), 225-229 (2007)

7. Lentz, B.R.: Exposure of platelet membrane phosphatidylserine regulates blood coagulation. Prog. Lipid Res. 42(5), 423-438 (2003)

8. Tyurina, Y.Y., Tyurin, V.A., Zhao, Q., Djukic, M., Quinn, J., Pitt, B.R., Kagan, V.E.: Oxidation of phosphatidylserine: A mechanism for plasma membrane phospholipid scrambling during apoptosis? Biochem. Biophys. Res. Commun. 324(3), 1059-1064 (2004)

9. Devaux, F.: The aminophospholipid translocase - A transmembrane lipid pump- Physiological significance. News Physiol. Sci. 5, 53-58 (1990)

10. Tyurina, Y.Y., Basova, L.V., Konduru, N.V., Tyurin, V.A., Potapovich, A.I., Cai, P., Bayir, H., Stoyanovsky, D., Pitt, B.R., Shvedova, A.A., Fadeel, B., Kagan, V.E.: Nitrosative stress inhibits the aminophospholipid translocase resulting in phosphatidylserine externalization and macrophage engulfment-implications for the resolution of inflammation. J. Biol. Chem. 282(11), 8498-8509 (2007)

11. Fruhwirth, G.O., Hermetter, A.: Mediation of apoptosis by oxidized phospholipids. Subcellular Biochem. 351-367 (2008)

12. Kagan, V.E., Gleiss, B., Tyurina, Y.Y., Tyurin, V.A., ElenstromMagnusson, C., Liu, S.X., Serinkan, F.B., Arroyo, A., Chandra, J., Orrenius, S., Fadeel, B.: A role for oxidative stress in apoptosis: Oxidation and externalization of phosphatidylserine is required for macrophage clearance of cells undergoing Fas-mediated apoptosis. $J$. Immunol. 169(1), 487-499 (2002)

13. Greenberg, M.E., Sun, M., Zhang, R.: Oxidized phosphatidylserineCD36 interactions play an essential role in macrophage-dependent phagocytosis of apoptotic cells. JEM 203(12), 2613-2625 (2006)

14. Kagan, V.E., Borisenko, G.G., Tyurina, Y.Y.: Oxidative lipidomics of apoptosis: Redox catalytic interactions of cytochrome $c$ with cardiolipin and phosphatidylserine. Free Radic. Biol. Med. 27(12), 983-1985 (2004)

15. Fruhwirth, G.O., Loidl, A., Hermetter, A.: Oxidized phospholipids: From molecular properties to disease. Biochim. Biophys. Acta 1772, 718-736 (2007)

16. Bochkov, V.N., Oskolkova, O.V., Birukov, K.G., Levonen, A.L., Binder, C.J., Stockl, J.: Generation and Biological Activities of Oxidized Phospholipids. Antioxid. Redox Signal. 12(8), 1009-1059 (2010)

17. Guan, Z.Q.: Discovering novel brain lipids by liquid chromatography/ tandem mass spectrometry. J. Chromatogr. B Anal. Technol. Biomed. Life Sci. 877(26), 2814-2821 (2009)

18. Hsu, F.-F., Turk, J.: Studies on Phosphatidylserine by Tandem Quadrupole and Multiple Stage Quadrupole Ion-Trap Mass Spectrometry with Electrospray Ionization: Structural Characterization and the Fragmentation Processes. J. Am. Soc. Mass Spectrom. 16(9), 15101522 (2005)

19. Hsu, F.-F., Turk, J.: Electrospray ionization with low-energy collisionally activated dissociation tandem mass spectrometry of glycerophospholipids: Mechanisms of fragmentation and structural characterization. J. Chromatogr. B 877(26), 2673-2695 (2009)

20. Domingues, M.R.M., Reis, A., Domingues: Mass spectrometry analysis of oxidized phospholipids. Chem. Phys. Lipids 156(1/2), 1-12 (2008)

21. Matsura, T., Togawa, A., Kai, M., Nishida, T., Nakada, J., Ishibe, Y., Kojo, S., Yamamoto, Y., Yamada, K.: The presence of oxidized phosphatidylserine on Fas-mediated apoptotic cell surface. Biochim. Biophys. Acta Mol. Cell Biol. Lipids 1736(3), 181-188 (2005)

22. Bayir, H., Fadeel, B., Palladino, M.J., Witasp, E., Kurnikov, I.V., Tyurina, Y.Y., Tyurin, V.A., Amoscato, A.A., Jiang, J., Kochanek, M., Dekosky, S.T., Greenberger, J.S., Shvedova, A.A., Kagan, V.E.: Apoptotic interactions of cytochrome $c$ : Redox flirting with anionic phospholipids within and outside of mitochondria. Biochim. Biophys. Acta Bioenergetics 1757(5/6), 648-659 (2006)

23. Tyurina, Y.Y., Tyurin, V.A., Epperly, M.W., Greenberger, J.S., Kagan, V.E.: Oxidative lipidomics of gamma-irradiation-induced intestinal injury. Free Rad. Biol. Med. 44(3), 299-314 (2008)

24. Bayir, H., Tyurin, V.A., Tyurina, Y.Y., Viner, R., Ritov, V., Amoscato, A.A., Zhao, Q., Zhang, X.J.J., Janesko-Feldman, K.L., Alexander, H., Basova, L.V., Clark, R.S.B., Kochanek, M., Kagan, V.E.: Selective early cardiolipin peroxidation after traumatic brain injury: An oxidative lipidomics analysis. Annals Neurosci. 62(2), 154-169 (2007)

25. Tyurin, V.A., Tyurina, Y.Y., Feng, W., Mnuskin, A., Jiang, J.F., Tang, M. K., Zhang, X.J., Zhao, Q., Kochanek, M., Clark, R.S.B., Bayir, H., Kagan, V.E.: Mass-spectrometric characterization of phospholipids and their primary peroxidation products in rat cortical neurons during staurosporine-induced apoptosis. J. Neurochem. 107(6), 1614-1633 (2008)

26. Tyurin, V.A., Tyurina, Y., Jung, M.Y., Tungekar, M.A., Wasserloos, K. J., Bayir, H., Greenberger, J.S., Kochanek, M., Shvedova, A.A., Pitt, B., Kagan, V.E.: Mass-spectrometric analysis of hydroperoxy- and hydroxy-derivatives of cardiolipin and phosphatidylserine in cells and tissues induced by pro-apoptotic and pro-inflammatory stimuli. $J$. Chromatogr. B 877(26), 2863-2872 (2009)

27. Reis, A., Domingues, P., Ferrer-Correia, A.J.V., Domingues, M.R.M.: Fragmentation study of short-chain products derived from oxidation of diacylphosphatidylcholines by electrospray tandem mass spectrometry: Identification of novel short-chain products. Rapid Commun. Mass Spectrom. 18(23), 2849-2858 (2004)

28. Maciel, E., Domingues, Marques, D., Simões, C., Reis, A., Oliveira, M.M., Videira, R.A., Peixoto, F., Domingues, M.R.M.: Cardiolipin and oxidative stress: Identification of new short chain oxidation products of cardiolipin in in vitro analysis and in nephrotoxic drug-induced disturbances in rat kidney tissue. Int. J. Mass Spectrom. 301(1-3), 62-73 (2011)

29. Domingues, M.R.M., Simões, C., Da Costa, J., Reis, A., Domingues, P.: Identification of 1-palmitoyl-2-linoleoyl-phosphatdylethanolamine modifications under oxidative stress conditions by LC-MS/MS. Biomed. Chromatogr. 23, 588-601 (2008)

30. Spiteller, P., Kern, W., Reiner, J., Spiteller, G.: Aldehydic lipid peroxidation products derived from linoleic acid. Biochim. Biophys. Acta Mol. Cell Biol. Lipids 1531(3), 188-208 (2001) 
31. Reis, A., Domingues, M.R.M., Amado, F.M.L., Ferrer-Correia, A.J.V., Domingues, P.: Separation of peroxidation products of diacyl-phosphatidylcholines by reversed-phase liquid chromatography-mass spectrometry. Biomed. Chromatogr. 19(2), 129-137 (2005)

32. Maciel, E., Domingues, Domingues, M.R.M.: Liquid chromatography/ tandem mass spectrometry analysis of long-chain oxidation products of cardiolipin induced by the hydroxyl radical. Rapid Commun. Mass Spectrom. 25(2), 316-326 (2011)

33. Domingues, M.R.M., Simoes, C., Da Costa, J., Reis, A., Domingues, P.: Identification of 1-palmitoyl-2-linoleoyl-phosphatidylethanolamine modifications under oxidative stress conditions by LC-MS/MS. Biomed. Chromatogr. 23(6), 588-601 (2009)

34. Shadyro, O., Yurkova, I., Kisel, M., Brede, O., Arnhold, J.: Formation of phosphatidic acid, ceramide, and diglyceride on radiolysis of lipids: Identification by MALDI-TOF mass spectrometry. Free Radic. Biol. Med. 36(12), 1612-1624 (2004)

35. Shadyro, O.I., Yurkova, I.L., Kisel, M.A., Brede, O., Arnhold, J.: Radiation-induced fragmentation of cardiolipin in a model membrane. Int. J. Radic. Biol. 80(3), 239-245 (2004)

36. Stadtman, E.R., Berlett, B.S.: Fenton Chemistry. J. Biol. Chem. 256 (26), 1701-17211 (1991)
37. Pulfer, M., Murphy, R.C.: Electrospray mass spectrometry of phospholipids. Mass Spectrom. Rev. 22(5), 332-364 (2003)

38. Reis, A., Domingues, P., Ferrer-Correia, A.J.V., Domingues, M.R.M.: Tandem mass spectrometry of intact oxidation products of diacylphosphatidylcholines: Evidence for the occurrence of the oxidation of the phosphocholine head and differentiation of isomers. J. Mass Spectrom. 39(12), 1513-1522 (2004)

39. Stadtman, E.R., Levine, R.L.: Free radical-mediated oxidation of free amino acids and amino cid residues in proteins. Amino Acids 25, 207-218 (2003)

40. Xu, G., Chance, M.R.: Hydroxyl radical-mediated modification of proteins as probes for structural proteomics. Chem. Rev. 107, 3514-3543 (2007)

41. Flemmig, J., Arnhold, J.: Interaction of hypochlorous acid and myeloperoxidase with phosphatidylserine in the presence of ammonium ions. J. Inorg. Biochem. 104(7), 759-764 (2010)

42. Flemmig, J., Spalteholz, H., Schubert, K., Meier, S., Arnhold, J.: Modification of phosphatidylserine by hypochlorous acid. Chem. Phys. Lipids 161(1), 44-50 (2009)

43. Davies, M.J.: Protein and peptide alkoxyl radicals can give rise to Cterminal decarboxylation and backbone cleavage. Arch. Biochem. Biophys. 336(1), 163-172 (1996) 